\title{
Effects of chronic trawling disturbance on the production of infaunal communities
}

\author{
Simon Jennings ${ }^{1, *}{ }^{,}$Mike D. Nicholson ${ }^{1}$, Tracy A. Dinmore ${ }^{1}$, John E. Lancaster ${ }^{2}$ \\ ${ }^{1}$ Centre for Environment, Fisheries \& Aquaculture Science, Lowestoft Laboratory, Lowestoft NR33 0HT, United Kingdom \\ ${ }^{2}$ School of Biological Sciences, University of Wales, Swansea SA2 8PP, United Kingdom
}

\begin{abstract}
Trawling causes widespread physical disturbance in shallow shelf seas. While the impacts of trawling on the biomass and community structure of benthic fauna are well known, no existing studies have quantified the effects of trawling disturbance on the absolute production of small benthic infauna. We investigated the effects of beam trawling disturbance on the production of small benthic infauna (AFDM $>0.78$ to $62.5 \mathrm{mg}$ ) at 9 sites that were subject to a 17.5 -fold range in annual trawling disturbance, using a size-based approach that could be applied to other soft-bottom systems. We developed a generalised additive model to test for relationships between trawling disturbance and infaunal production and size structure, after accounting for differences in sediment characteristics and depth. The statistical power of our analyses to detect linear and non-linear relationships between production and disturbance, including increased production at intermediate levels of disturbance, was high (>90\% probability of detecting a $50 \%$ change in production across the range of disturbance). The analyses showed that trawling frequencies of 0.35 to 6.14 times $\mathrm{yr}^{-1}$ did not have a significant effect on the production of small infauna or polychaetes. This result contrasts with order of magnitude decreases in the production of large infauna, and shows that small polychaetes with fast life histories are less vulnerable to trawling disturbance. Since small infaunal polychaetes are a key source of food for flatfishes, we conclude that beam trawling disturbance does not have a positive or negative effect on their food supply.
\end{abstract}

KEY WORDS: Fishing effects $\cdot$ Size spectra $\cdot$ Production $\cdot$ Infauna $\cdot$ Disturbance $\cdot$ Power analysis

\section{INTRODUCTION}

Bottom trawling causes chronic and widespread disturbance to soft-sediment communities in shelf seas (De Groot \& Lindeboom 1994, Jennings \& Kaiser 1998, Lindeboom \& de Groot 1998, Hall 1999, Collie et al. 2000b, Kaiser \& De Groot 2000). The relative impacts of this disturbance depend on the frequency of trawling and levels of natural disturbance. In general, studies of trawling impacts have compared community structure at sites subject to different intensities of trawling disturbance; usually based on multivariate analysis of transformed species abundance data. Such

*Email: s.jennings@cefas.co.uk studies have focused on impacts on larger macrofauna and habitat forming species, primarily because reductions in their abundance and diversity are an important conservation issue, and because they provide habitat for bottom-dwelling fishes (Auster \& Langton 1999, Collie et al. 2000a,b, Koslow et al. 2001). Few studies have considered the implications of trawling disturbance on ecosystem processes (Duplisea et al. 2001). Such processes include the production of the benthic community and its role in supporting the production of fished species which, from a human perspective, is an important function of the marine ecosystem.

Infauna are an important link in the food chains supporting fish production. Commercially important flatfishes such as plaice Pleuronectes platessa and sole Solea solea, that live on open sand and mud-sand sea 
beds (Kaiser et al. 1999), feed predominantly on infaunal polychaetes (Braber \& De Groot 1973, De Clerck \& Buseyne 1989). Since the advent of beam trawling in parts of the NE Atlantic, there have been increases in the growth rates of flatfishes, and these have been linked to improved feeding conditions (Rijnsdorp \& Vingerhoed 2001, Rijnsdorp \& Van Leeuwen 1996). This implies that there may have been absolute increases in the abundance of small polychaetes in trawled areas (Rijnsdorp \& Van Leeuwen 1996), although the analysis is complicated by increases in primary production over the same period (Kroncke et al. 1998, Reid et al. 1998). Small infauna could proliferate in response to trawling disturbance because trawling significantly reduces the biomass of larger benthic fauna (Bergman \& Van Santbrink 2000a,b, Kaiser et al. 2000, Jennings et al. 2001a), and other organisms that can withstand trawling disturbance may benefit from reduced competition. The only organisms likely to do this will have small body sizes and high intrinsic rates of increase, characteristics that reduce their vulnerability to trawling (Gilkinson et al. 1998, Bergman \& Van Santbrink 2000a,b).

The only existing study of trawling impacts on infaunal production showed that there were 6 -fold reductions in total community production across a gradient of trawling disturbance (Jennings et al. 2001a). This study focused on an assessment of the relative production of larger infauna, and the reductions in production were largely due to reductions in the biomass of large bivalves and spatangoids, species that are very vulnerable to trawling (Rumohr \& Krost 1991, Bergman \& Van Santbrink 2000a,b, Rumohr \& Kujawski 2000). Multivariate analyses (Clarke \& Ainsworth 1993) showed that the reduction in biomass and production of larger animals was due to trawling effects rather than sediment type or depth (Duplisea et al. in press). The results were clear for the large bivalves and spatangoids that play a key role in bioturbation and community production; however, for the small polychaetes and bivalves that support flatfish production, the sampling design and analysis provided little power to determine the effects of trawling.

Size-based analyses provide a useful approach for studying the impacts of trawling disturbance on production processes because mortality rates and the capacity to sustain elevated mortality are functions of body size (Brey 1990, 1999). Marine soft-sediment communities have characteristic distributions of biomass among body mass classes, and analyses of these size spectra have been used to describe structure and energy flux in ecosystems (Schwinghamer et al. 1986, Duplisea 2000). Within a size spectrum, ecological processes such as production are treated solely as a function of body mass and thus, a small individual of a large species is equivalent to a large individual of a small species in the same body mass class. Changes in the slopes and intercepts of the size spectra reflect changes in body-size distribution in the community and can indicate whether the depletion of larger individuals leads to increased biomass or production in smaller size classes.

Most studies of trawling effects have relied on experiments. These experiments are often short-term and do not reflect the chronic disturbance caused by trawls in real fisheries. To assess the impacts of trawling disturbance at the scale of the fishery requires knowledge of temporal and spatial variation in trawling intensity, data that are rarely available on appropriate scales (Collie et al. 1997, Thrush et al. 1998, Kaiser et al. 2000, Jennings et al. 2001a,b). If quantified levels of trawling disturbance in real fisheries could be linked to quantifiable changes in the production of benthic communities, this would be a first step towards predicting and mitigating any undesirable and indirect effects of fishing on the ecosystem processes that lead to fish production.

The aim of this study is to investigate the effects of beam trawling disturbance on the production of the smaller size classes of benthic infauna that support flatfish production. We use a size-based approach that could be applied to other soft-bottom systems. Our study was conducted on real fishing grounds with a quantified history of trawling disturbance. We used a generalised additive model (Hastie \& Tibshirani 1990) to test for the effect of trawling disturbance, and to account for differences in sediment type and depth that could also affect infaunal production. Because the variation in these predictor variables was not controlled, it is important to quantify how effective the statistical analyses of these data are likely to be. This is particularly important when interpreting statistical non-significance under a precautionary regime (Peterman \& M'Gonigle 1992). We have therefore assessed the statistical power of all our analyses to detect (1) linear increases and decreases in infaunal production; and (2) increased production at intermediate levels of disturbance.

\section{MATERIALS AND METHODS}

Study site. The Silver Pit region of the central North Sea (Fig. 1a) is a relatively homogeneous area of sand and mud sediment that is regularly fished by beam trawlers targeting sole and plaice. The Silver Pit is 50 to $75 \mathrm{~m}$ deep, with mean winter and summer temperatures of 5 and $13.5^{\circ} \mathrm{C}$, respectively. The production of benthic communities was studied at 9 sites in the Silver Pit (Fig. 1b). Sites were $5 \mathrm{n}$ miles $(9.3 \mathrm{~km})$ north-south 
a)

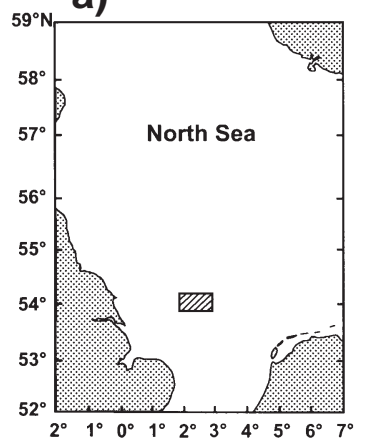

b)

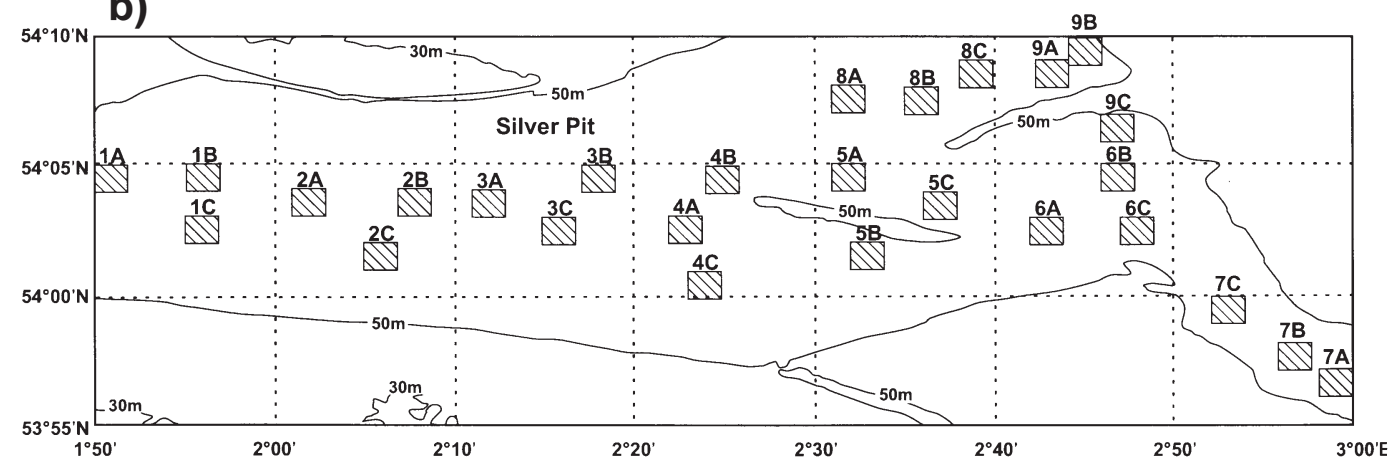

Fig. 1. The Silver Pit region in (a) the central North Sea and (b) the location of Sites 1 to 9 and Boxes A, B and C within the Silver Pit. The 30 and $50 \mathrm{~m}$ depth contours are shown

by $6 \mathrm{n}$ miles east-west $(11.1 \mathrm{~km})$, and were selected haphazardly in an area where there were known to be spatial variations in the frequency of trawling disturbance (Jennings et al 2000). Within each site, we sampled the infaunal community in 3 boxes of $1 \mathrm{n}$ mile north-south by $1 \mathrm{n}$ mile east-west $(1 \mathrm{n}$ mile $=1.85 \mathrm{~km})$. Boxes were haphazardly located within sites.

Sample collection and processing. Benthic infauna were sampled with a NIOZ (Netherlands Institute for Sea Research) corer. This device takes a circular sediment core of $35.7 \mathrm{~cm}$ internal diameter (area of $0.1 \mathrm{~m}^{2}$ ) to a depth of $40 \mathrm{~cm}$. Ten cores were taken from each of the 27 boxes, 5 from 21 November to 4 December 2000 and 5 from 5 to 18 April 2001, to account for the variations in size structure that result from 'pulses' of recruits growing up the size spectrum. Core samples were sieved through $1 \mathrm{~mm}^{2}$ mesh. All infaunal species retained by the mesh were removed for processing and preserved in $4 \%$ formalin diluted with seawater and buffered with $3 \mathrm{~g} \mathrm{l}^{-1}$ sodium acetate. A sediment sample was also taken from each core for particle size analysis (Dyer 1986). This was removed with a $5.5 \mathrm{~cm}$ diameter perspex tube and frozen to $-20^{\circ} \mathrm{C}$ pending analysis. After thawing, sediment samples were wetsieved through a $500 \mu \mathrm{m}$ sieve and the fraction greater than $500 \mu \mathrm{m}$ was oven-dried at $90^{\circ} \mathrm{C}$ for $24 \mathrm{~h}$. This fraction was then dry-sieved at 0.5 phi intervals, down to 1 phi $(500 \mu \mathrm{m})$ and weighed on a top pan balance (precision $=0.01 \mathrm{~g}$ ). The fraction smaller than $500 \mu \mathrm{m}$ was freeze-dried and analysed on a Coulter LS 130 laser sizer. The laser sizer results were combined with the dry-sieve results to give the full particle size distribution. The mean particle size diameter and sorting coefficient were calculated from these results (Dyer 1986).

In the laboratory, infaunal samples were sorted to higher taxonomic categories (from genus to phylum) and individual animals were weighed (blotted wet weight) to the nearest $0.001 \mathrm{~g}$. Tube-forming polychaetes were removed from tubes before weighing. We did not apply shrinkage factors to account for weight changes following preservation as these were not available for the very wide range of species included in our samples. As this study dealt with the production of benthic animals that would be available to support production at higher trophic levels, we converted wet weight to ash-free dry mass (AFDM) using conversion factors kindly provided by Thomas Brey (pers. comm.). All individuals with a calculated AFDM of $\leq 62.5 \mathrm{mg}$ were included as they were small infauna in the size classes eaten by many fishes and effectively sampled with the NIOZ corer. Inevitably, a proportion of the animals in our samples were damaged or incomplete. We applied the following rules to damaged specimens. First, we tried to assemble 'complete' animals from the fragments in the sample, and recorded these as a single individual. Second, if fragments of an animal constituted less than $30 \%$ of the expected mass of a complete animal, we discarded them.

Trawling disturbance. Mean levels of trawling disturbance at the study sites were determined from records of beam trawler sightings by fishery protection aircraft. These aircraft patrol the fishing grounds around the United Kingdom and record a description and location for all vessels they observe fishing. Trawling disturbance can therefore be estimated as the number of beam trawler sightings per unit of aircraft search effort (SPUE). Within each site, we calculated beam trawler SPUE on an annual basis from 1994 to 2000. Sightings were the number of times that a beam trawler was recorded at each site and search effort was the number of times that an aircraft visited the site (Jennings et al. 2000). We assumed that beam trawler SPUE was directly and linearly proportional to trawling effort and trawling disturbance (Jennings et al. 2001a).

The SPUE data were converted to a mean frequency of beam trawling at each site. We assumed that the average beam trawler fishing in the Silver Pit will tow two $12 \mathrm{~m}$ wide beams at a speed of 6 knots $(11.1 \mathrm{~km}$ $\mathrm{h}^{-1}$ ), and that $267264 \mathrm{~m}^{2}$ of seabed will be disturbed 
each hour. Therefore, an annual SPUE of 1 (beam trawler always sighted at the site) should equate to the entire area of the site being trawled, on average, 22.73 times $\mathrm{yr}^{-1}$. In reality, trawling effort within the site will be patchy and some areas will be trawled more frequently than others. However, the mean frequency of trawling provides a useful comparative index of disturbance, and side-scan observations of trawl tracks within the Silver Pit study sites (where the sediment is sufficiently soft for trawl tracks to persist for a few days after trawling) suggest that tracks cross the more heavily fished sites in many directions (T. A. Dinmore \& S. Jennings unpubl. data).

Data analyses. Body size spectra were produced for the infaunal communities at each site. Biomass by size class $\left(\log _{2}\right.$ AFDM classes for all animals of AFDM $\leq 62.5 \mathrm{mg}$ ) was calculated for each box in each site as the means for the 10 replicates cores from 2 seasons. Biomass size spectra were normalised by dividing the biomass in a given body mass class interval by the width of that class interval. The relationship between size (as classes) and total normalised biomass was described using least-squares linear regression.

Production was calculated from biomass using an allometric relationship between P:B and mean AFDM. This was calculated using the subset of Brey's (1999) data set described in Jennings et al. (2001a). The relationship for the same species, but parameterised for AFDM, was $\log _{10} \mathrm{P}: \mathrm{B}=-0.431-\left(0.236 \times \log _{10} \mathrm{~B}\right)$. Total production of animals $>0.78$ to $62.5 \mathrm{mg}$ AFDM (boundaries of the size range were selected to correspond with the boundaries of the $\log _{2}$ AFDM classes) was calculated as the sum of production estimates in the appropriate $\log _{2}$ AFDM classes.

Following a preliminary assessment of the data, each effect variable was analysed using a generalised additive model of the form:

$$
y_{i}=a_{0}+a_{1} x_{1 i}+a_{2} x_{1 i}{ }^{2}+a_{3} x_{2 i}+a_{4} x_{3 i}+l o\left(x_{4 i}\right)+\varepsilon_{i}
$$

for observation $i_{1}$, where $x_{1 i}=$ mean particle diameter, $x_{2 i}=$ sorting coefficient, $x_{3 i}=$ depth, $x_{4 i}=$ trawling disturbance, $l o($.) indicates a loess smoother and $\varepsilon_{i}$ is normally distributed with constant variance.

The smoother was given approximately 3 degrees of freedom, corresponding to a span of 0.66 , and each term was fitted and tested sequentially at the $5 \%$ significance level.

Post hoc power analyses were used to assess the power of our analysis to detect a linear trend in the production of all small animals or small polychaetes (>0.78 to $62.5 \mathrm{mg}$ AFDM).
Power was calculated as a function of the percentage change from the mean response to mean response \pm $50 \%$ over the range from the minimum to the maximum frequency of trawl disturbance. Post hoc power analyses were also used to assess the power of our analysis to detect a linear trend in the slope and intercept of the biomass size spectra.

Since non-linear responses to trawl disturbance may arise, we also tested the power of our analyses to detect non-linear trends in the production of small animals or small polychaetes. The most likely forms of non-linear response are those that reflect increased production at some intermediate level of disturbance where, for example, small animals would benefit from reduced competition or predation, but where the rates of population growth would be sufficiently high to tolerate mortality due to trawling. To incorporate a range of possible response scenarios, a family of hypothetical responses were generated using a function of the form:

$$
\text { response }_{i}=\text { constant } \times x_{i}^{a}\left(1-x_{i}\right)^{a}
$$

where $x_{i}=x_{4 i}-\min \left(x_{4 i}\right) /\left[\max \left(x_{4 i}\right)-\min \left(x_{4 i}\right)\right]$ is the $i$ th proportion of trawl disturbance, and the constant scales the maximum of the response curve to be constant for different values of a shape parameter, $a$. When $a=0$, the function describes a negative linear response and when $a=1$, a positive linear response. For intermediate values of $a$, the function describes higher levels of production at intermediate levels of disturbance.

\section{RESULTS}

All the study sites were trawled. There was a 17.5-fold range in the mean frequency of beam trawling disturbance among the Silver Pit study sites (maximum frequency 6.14 , minimum frequency 0.35 ; Table 1 ). The

Table 1. Mean annual sightings per unit searching effort (SPUE) of beam trawlers by fishery protection flights at the Silver Pit study sites, and the mean number of times the sites are beam-trawled each year. Data are based on 1517 sightings of beam trawlers from 1 January 1994 to 31 December 2000

\begin{tabular}{|ccccc|}
\hline Site code & $\begin{array}{c}\text { Mean SPUE } \\
\text { (number visit }^{-1} \text { ) }\end{array}$ & $95 \%$ CI & $\begin{array}{c}\text { Mean frequency } \\
{\text { (times trawled } \mathrm{yr}^{-1} \text { ) }}^{\text {(tim }}\end{array}$ \\
\hline 1 & 0.04 & 0.015 & 0.98 & 0.346 \\
2 & 0.10 & 0.044 & 2.29 & 1.019 \\
3 & 0.18 & 0.044 & 4.11 & 1.013 \\
4 & 0.22 & 0.103 & 4.94 & 2.354 \\
5 & 0.27 & 0.101 & 6.14 & 2.311 \\
6 & 0.22 & 0.099 & 5.10 & 2.263 \\
7 & 0.02 & 0.010 & 0.35 & 0.229 \\
8 & 0.15 & 0.063 & 3.44 & 1.452 \\
9 & 0.10 & 0.040 & 2.37 & 0.924 \\
\hline
\end{tabular}


Table 2. Depth and sediment characteristics at the Silver Pit sites; except Phi, data are mean $\pm 95 \%$ CI

\begin{tabular}{|c|c|c|c|c|c|c|}
\hline $\begin{array}{l}\text { Site/ } \\
\text { box code }\end{array}$ & $\begin{array}{l}\text { Depth } \\
\text { (m) }\end{array}$ & $\begin{array}{c}\text { Sediment } \\
\text { diameter (mm) }\end{array}$ & Phi & $\begin{array}{c}\text { Sediment } \\
\text { sorting coefficient }\end{array}$ & $\begin{array}{c}\text { Sand } \\
\text { (\% by weight) }\end{array}$ & $\begin{array}{c}\text { Mud/silt } \\
\text { (\% by weight) }\end{array}$ \\
\hline $1 \mathrm{~A}$ & $74.1 \pm 1.7$ & $0.053 \pm 0.007$ & 4.26 & $2.432 \pm 0.060$ & $63.1 \pm 2.8$ & $36.9 \pm 2.8$ \\
\hline $1 \mathrm{~B}$ & $69.1 \pm 0.5$ & $0.056 \pm 0.009$ & 4.19 & $2.263 \pm 0.083$ & $67.4 \pm 4.2$ & $32.6 \pm 4.2$ \\
\hline $1 \mathrm{C}$ & $74.8 \pm 1.3$ & $0.081 \pm 0.013$ & 3.65 & $2.364 \pm 0.091$ & $74.9 \pm 2.0$ & $25.1 \pm 2.0$ \\
\hline $2 \mathrm{~A}$ & $69.3 \pm 1.3$ & $0.058 \pm 0.019$ & 4.20 & $2.378 \pm 0.076$ & $65.4 \pm 8.2$ & $34.6 \pm 8.2$ \\
\hline $2 \mathrm{~B}$ & $69.9 \pm 0.6$ & $0.047 \pm 0.006$ & 4.42 & $2.484 \pm 0.060$ & $59.8 \pm 5.0$ & $40.2 \pm 5.0$ \\
\hline $2 \mathrm{C}$ & $70.0 \pm 1.8$ & $0.085 \pm 0.020$ & 3.60 & $2.349 \pm 0.087$ & $75.9 \pm 5.7$ & $24.1 \pm 5.7$ \\
\hline $3 \mathrm{~A}$ & $71.7 \pm 0.5$ & $0.052 \pm 0.028$ & 4.43 & $2.382 \pm 0.128$ & $62.9 \pm 9.5$ & $37.1 \pm 9.5$ \\
\hline 3B & $64.7 \pm 1.1$ & $0.053 \pm 0.009$ & 4.27 & $2.439 \pm 0.106$ & $64.6 \pm 4.8$ & $35.4 \pm 4.8$ \\
\hline $3 \mathrm{C}$ & $69.7 \pm 1.5$ & $0.048 \pm 0.007$ & 4.39 & $2.318 \pm 0.078$ & $63.1 \pm 3.0$ & $36.4 \pm 3.3$ \\
\hline $4 \mathrm{~A}$ & $64.3 \pm 1.3$ & $0.063 \pm 0.018$ & 4.04 & $2.322 \pm 0.117$ & $69.7 \pm 6.3$ & $30.3 \pm 6.3$ \\
\hline $4 \mathrm{~B}$ & $68.3 \pm 0.3$ & $0.044 \pm 0.003$ & 4.50 & $2.263 \pm 0.038$ & $64.3 \pm 3.2$ & $35.7 \pm 3.2$ \\
\hline $4 \mathrm{C}$ & $66.5 \pm 0.5$ & $0.062 \pm 0.014$ & 4.03 & $2.143 \pm 0.188$ & $74.8 \pm 6.9$ & $25.1 \pm 6.9$ \\
\hline $5 \mathrm{~A}$ & $64.8 \pm 0.3$ & $0.039 \pm 0.010$ & 4.74 & $2.369 \pm 0.172$ & $63.9 \pm 3.4$ & $38.7 \pm 5.8$ \\
\hline $5 B$ & $63.4 \pm 2.0$ & $0.036 \pm 0.003$ & 4.81 & $2.316 \pm 0.077$ & $57.8 \pm 2.9$ & $42.2 \pm 2.9$ \\
\hline $5 \mathrm{C}$ & $60.2 \pm 0.6$ & $0.078 \pm 0.022$ & 3.73 & $2.386 \pm 0.113$ & $73.3 \pm 5.7$ & $26.7 \pm 5.7$ \\
\hline $6 \mathrm{~A}$ & $60.7 \pm 0.4$ & $0.027 \pm 0.002$ & 5.24 & $2.339 \pm 0.041$ & $47.6 \pm 2.0$ & $52.4 \pm 2.0$ \\
\hline $6 \mathrm{~B}$ & $68.8 \pm 3.9$ & $0.016 \pm 0.003$ & 5.99 & $2.247 \pm 0.095$ & $25.3 \pm 8.0$ & $74.7 \pm 8.0$ \\
\hline $6 \mathrm{C}$ & $61.1 \pm 0.6$ & $0.033 \pm 0.001$ & 4.92 & $2.301 \pm 0.046$ & $54.7 \pm 0.7$ & $45.3 \pm 0.7$ \\
\hline $7 \mathrm{~A}$ & $59.8 \pm 0.7$ & $0.015 \pm 0.002$ & 6.03 & $2.299 \pm 0.031$ & $25.9 \pm 2.8$ & $74.1 \pm 2.8$ \\
\hline $7 \mathrm{~B}$ & $60.4 \pm 0.5$ & $0.018 \pm 0.002$ & 5.87 & $2.366 \pm 0.024$ & $31.8 \pm 4.5$ & $68.2 \pm 4.5$ \\
\hline $7 \mathrm{C}$ & $58.9 \pm 0.6$ & $0.018 \pm 0.003$ & 5.83 & $2.382 \pm 0.085$ & $32.2 \pm 4.0$ & $67.6 \pm 4.2$ \\
\hline $8 \mathrm{~A}$ & $62.9 \pm 0.2$ & $0.039 \pm 0.004$ & 4.69 & $2.203 \pm 0.054$ & $61.2 \pm 3.2$ & $38.8 \pm 3.2$ \\
\hline $8 \mathrm{~B}$ & $59.1 \pm 0.3$ & $0.037 \pm 0.005$ & 4.76 & $2.295 \pm 0.057$ & $55.9 \pm 4.4$ & $44.1 \pm 4.4$ \\
\hline $8 \mathrm{C}$ & $61.3 \pm 0.6$ & $0.034 \pm 0.003$ & 4.88 & $2.217 \pm 0.034$ & $55.3 \pm 4.5$ & $44.7 \pm 4.5$ \\
\hline $9 \mathrm{~A}$ & $48.3 \pm 0.6$ & $0.035 \pm 0.004$ & 4.83 & $2.271 \pm 0.055$ & $58.0 \pm 4.2$ & $42.0 \pm 4.2$ \\
\hline $9 \mathrm{~B}$ & $59.7 \pm 0.4$ & $0.034 \pm 0.004$ & 4.91 & $2.289 \pm 0.051$ & $56.0 \pm 4.8$ & $44.0 \pm 4.8$ \\
\hline $9 \mathrm{C}$ & $58.1 \pm 4.1$ & $0.056 \pm 0.018$ & 4.21 & $2.275 \pm 0.230$ & $68.6 \pm 7.7$ & $31.4 \pm 7.7$ \\
\hline
\end{tabular}

$95 \%$ confidence intervals for trawling frequency showed that there was considerable inter-annual variation in the frequency of trawling at some sites. The trawled sites and boxes ranged from 48.3 to $74.8 \mathrm{~m}$ deep and were predominantly sandy or muddy-sand with mean particle size diameters ranging from 0.015 to $0.081 \mathrm{~mm}$. The variance in sediment particle diameter within boxes was low (Table 2).

\section{Biomass size spectra}

The slopes of the infaunal biomass size spectra were all significant and negative, and ranged from -0.10 to -0.25 (Table 3). The relationships between the slopes and intercepts of the biomass size spectra and the environmental variables and trawling disturbance (Table 4a) showed that the slopes were significantly related to mean particle diameter (MPD) and $\mathrm{MPD}^{2}$, and that after the model had been fitted, there was no evidence for a change in the slopes of the biomass size spectra with trawling disturbance (Fig. 2a). The post hoc power analysis showed that the power to detect a change of $\pm 20 \%$ in slope due to disturbance would have been high (Fig. 3) The intercepts were significantly related to the sorting coefficient (SC) and depth,

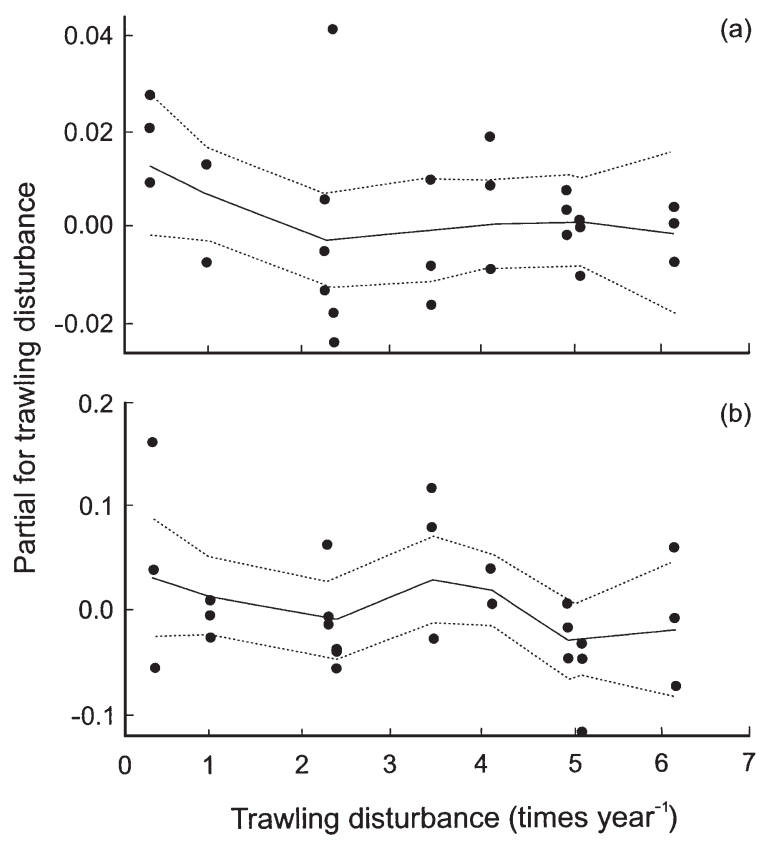

Fig. 2. Partial regressions of (a) the slopes and (b) intercepts of the biomass size spectra having fitted the mean particle diameter (MPD), MPD ${ }^{2}$, sorting coefficient and depth. The solid line is a fitted loess smoother with approximately $3 \mathrm{df}$ and a span of 0.66 , the broken lines show the lower and upper $95 \%$ confidence limits for this line 
and after the model had been fitted, there was no evidence for a significant change in the intercepts of the biomass size spectra with trawling disturbance (Fig 2b, Table $4 \mathrm{~b}$ ). The power to detect a change of $\pm 50 \%$ in the intercepts with disturbance was also high (Fig. 3).

\section{Production}

The production ( $\mathrm{g}$ AFDM m $\mathrm{m}^{-2} \mathrm{yr}^{-1}$ ) of all small animals (AFDM > 0.78 to $62.5 \mathrm{mg}$ ) in the community (Table 5) was significantly related to MPD, MPD ${ }^{2}, \mathrm{SC}$ and depth, and after these effects were accounted for in the generalised additive model, there was no evidence for a significant effect of trawling on production (Fig. 4a). The production (g AFDM m-2 $\mathrm{yr}^{-1}$ ) of small polychaetes (AFDM $>0.78$ to $62.5 \mathrm{mg}$ ) in the community (Table 5) was significantly related to MPD, MPD ${ }^{2}$ and depth $(p=0.06)$ (Table 4c). After these effects were accounted for in the model, there was no evidence for a significant linear effect of trawling on production (Fig. 4b). The power to detect linear and non-linear responses (as defined by parameter a, Fig. 5) of small animals and polychaetes was high. Thus, the post hoc power analysis showed that there was a minimum $90 \%$

Table 3. Slopes, intercepts and significance of linear regressions used to describe infaunal size spectra (plots of $\log _{10}$ normalised ash-free dry mass per sample by $\log _{2}$ size class vs $\log _{2}$ size class for all individuals $\leq 62.5 \mathrm{mg}$ AFDM)

\begin{tabular}{|lccccc|}
\hline $\begin{array}{l}\text { Site/ } \\
\text { box code }\end{array}$ & $a$ & $b$ & $\mathrm{r}^{2}$ & $F_{1,8}$ & $\mathrm{p}$ \\
\hline 1A & 0.30 & -0.23 & 0.90 & 70.5 & $<0.001$ \\
1B & 0.20 & -0.24 & 0.90 & 74.4 & $<0.001$ \\
1C & 0.25 & -0.22 & 0.87 & 52.3 & $<0.001$ \\
2A & 0.23 & -0.25 & 0.89 & 64.4 & $<0.001$ \\
2B & 0.29 & -0.24 & 0.86 & 49.8 & $<0.001$ \\
2C & 0.32 & -0.20 & 0.87 & 55 & $<0.001$ \\
3A & 0.27 & -0.25 & 0.93 & 106.4 & $<0.001$ \\
3B & 0.29 & -0.21 & 0.94 & 114.6 & $<0.001$ \\
3C & 0.27 & -0.22 & 0.95 & 155.9 & $<0.001$ \\
4A & 0.18 & -0.23 & 0.92 & 97.5 & $<0.001$ \\
4B & 0.17 & -0.21 & 0.88 & 60.3 & $<0.001$ \\
4C & 0.15 & -0.22 & 0.86 & 49.6 & $<0.001$ \\
5A & 0.31 & -0.22 & 0.88 & 52.8 & $<0.001$ \\
5B & 0.22 & -0.20 & 0.90 & 68.5 & $<0.001$ \\
5C & 0.14 & -0.22 & 0.88 & 57.9 & $<0.001$ \\
6A & 0.22 & -0.19 & 0.94 & 135.4 & $<0.001$ \\
6B & 0.18 & -0.14 & 0.82 & 35.2 & $<0.001$ \\
6C & 0.18 & -0.20 & 0.84 & 43.2 & $<0.001$ \\
7A & 0.45 & -0.10 & 0.73 & 21.8 & $<0.001$ \\
7B & 0.24 & -0.14 & 0.74 & 23 & $<0.001$ \\
7C & 0.33 & -0.13 & 0.79 & 31.4 & $<0.001$ \\
8A & 0.15 & -0.22 & 0.85 & 45.7 & $<0.001$ \\
8B & 0.28 & -0.22 & 0.94 & 117.2 & $<0.001$ \\
8C & 0.31 & -0.19 & 0.81 & 34.9 & $<0.001$ \\
9A & 0.11 & -0.22 & 0.86 & 48 & $<0.001$ \\
9B & 0.17 & -0.22 & 0.91 & 79.1 & $<0.001$ \\
9C & 0.10 & -0.18 & 0.76 & 25.6 & $<0.001$ \\
\hline & & & & & \\
\hline
\end{tabular}

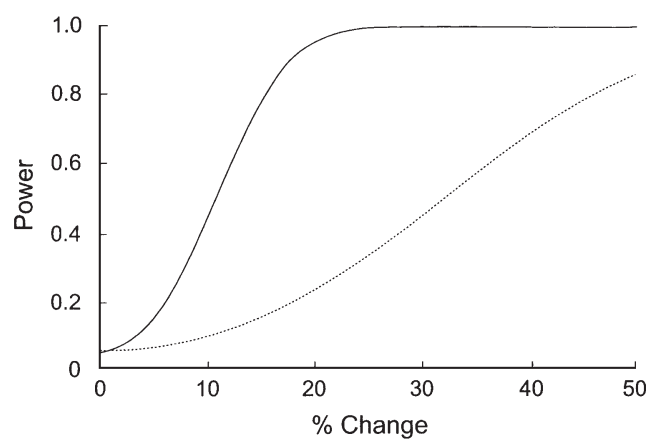

Fig. 3. The power of detecting significant linear relationships between the slopes (continuous line) and intercepts (broken line) of the biomass size spectra and trawling disturbance

probability of detecting a $50 \%$ change in the production of small animals, whether that change was positive, negative or resulted in increased production at intermediate levels of disturbance (Fig. 6).

\section{DISCUSSION}

Our results suggest that chronic beam trawling disturbance has minimal effects on the production and size structure of small benthic infauna. This conclusion is likely to be robust because the power of our analyses to detect small negative or positive changes in produc-

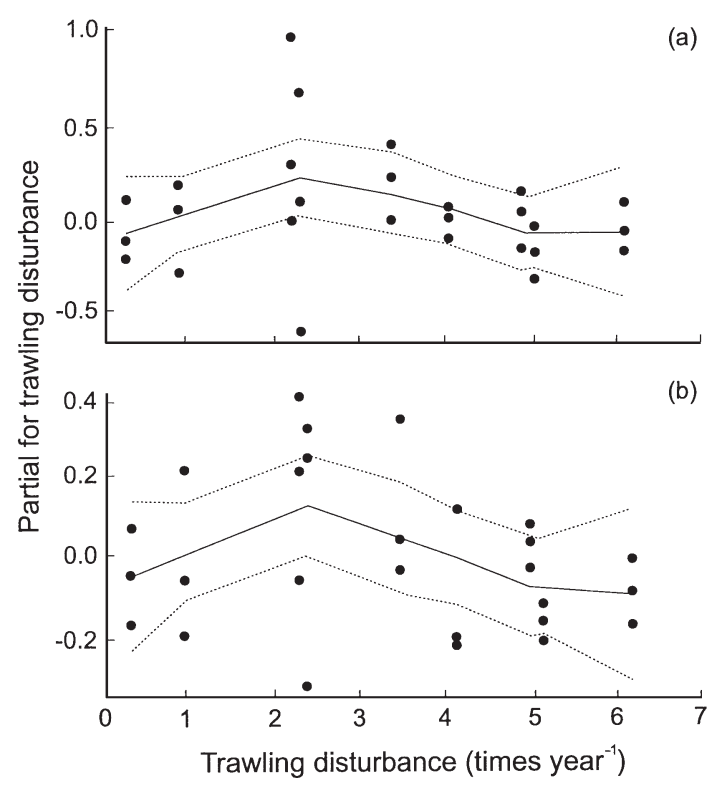

Fig. 4. Partial regressions of production of (a) small animals and (b) polychaetes having fitted the mean particle diameter (MPD), MPD ${ }^{2}$, sorting coefficient and depth. The solid line is a fitted loess smoother with approximately $3 \mathrm{df}$ and a span of 0.66 , the broken lines show the lower and upper $95 \%$ confidence limits for this line 


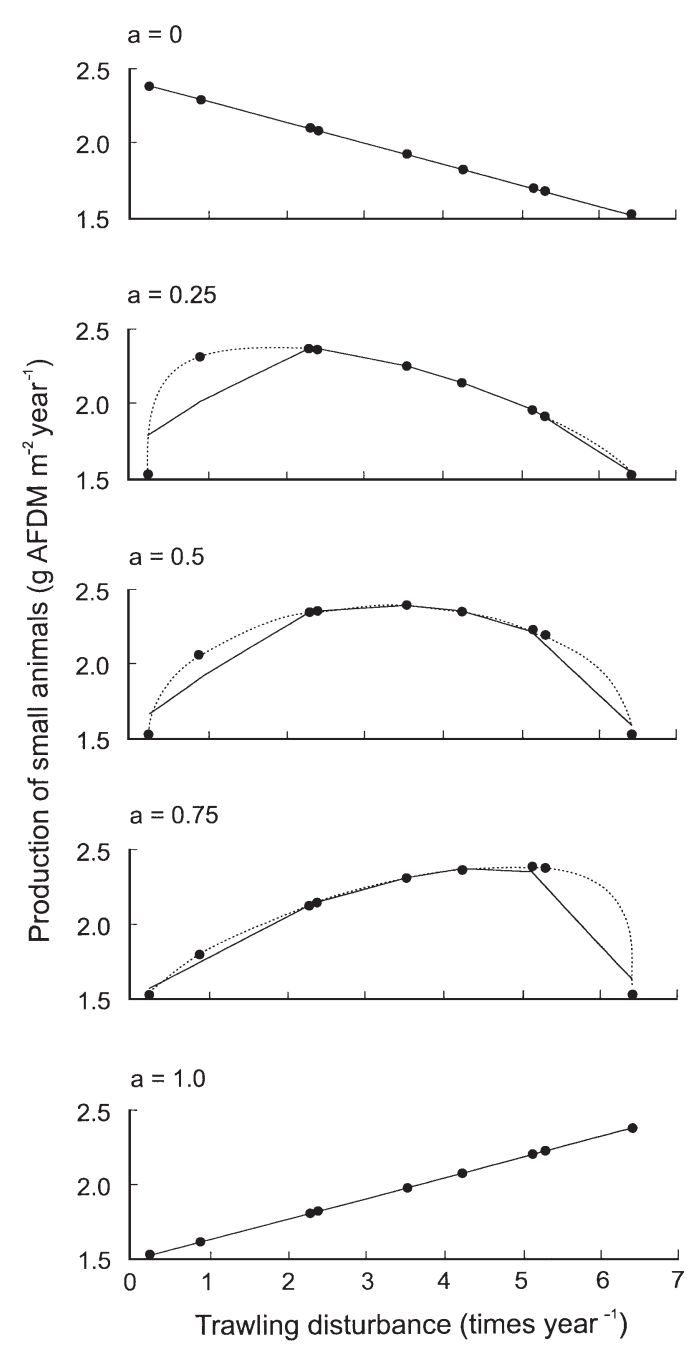

Fig. 5. Hypothetical responses of small animal or polychaete production to trawling disturbance for different values of the shape parameter $a$. Values corresponding to the observed trawl disturbances are shown as filled circles, and the solid lines show the degree to which the loess smoother is able to track the response curve

tion, or increased production at intermediate levels of disturbance, is high. Our results can probably be generalised to other shallow, trawled, sand and mud habitats dominated by free-living species. We would expect, however, very different results in areas where the habitat is more complex, especially where there are many biogenic species and where there was no previous history of fishing activity (e.g. Collie et al. 1997, 2000a,b, Auster \& Langton 1999). The small infauna we studied are among the few groups of benthic invertebrates for which biomass and production do not appear to be reduced by trawling disturbance. Since small infaunal polychaetes are a key source of food for flatfishes (Rijnsdorp \& Vingerhoed 2001), we conclude that beam trawling disturbance has a relatively minor impact on the food chains that support the production of the primary target species (plaice and sole). Our results also suggest that beam trawling is not 'farming the sea' by boosting production at intermediate levels of disturbance, even though trawling may expose small infauna and increase their availability to fishes and other predators (Ramsay et al. 1997). Moreover, our results show that the size distribution of small infauna is not markedly affected by trawling, even though the power of our analyses to detect an effect is high.

Our results contrast with the results of studies that have focused on trawling impacts on larger infauna or biogenic epifauna (e.g. Kenchington et al. 2001, Thrush et al. 2001). For example, studies of the impacts of trawling on the production of larger infauna in the central North Sea showed that there were 6 -fold reductions in production, and order of magnitude reductions in the biomass of bivalves and spatangoids across trawling frequencies of 0.2 to 6.5 times $\mathrm{yr}^{-1}$ (Jennings et al. 2001b). If there had been comparable changes in the relative production of the smaller animals that we considered in this study, then the design of our experiment and power of our analyses would have ensured that the changes were detected. For example, the power analysis showed that we had a minimum $90 \%$ probability of detecting a $50 \%$ change in the mean production of small animals, whether that change was a positive, negative or resulted in increased production at intermediate levels of disturbance. Our results suggest that only the smaller animals have sufficient rates

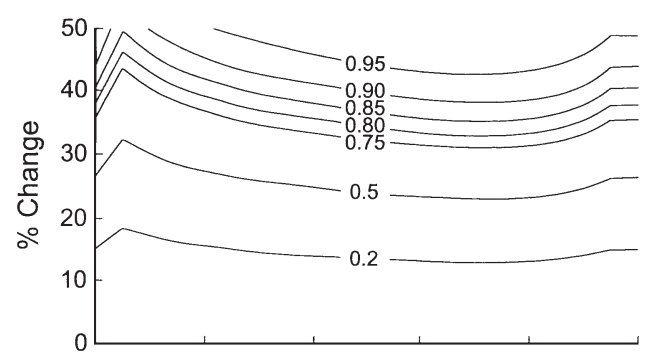

(a)

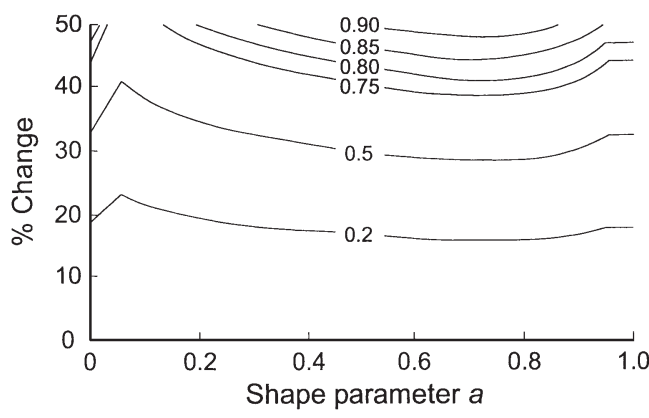

(b)

Fig. 6. The power of our analyses for (a) small animals and (b) polychaetes to detect a significant impact of trawling disturbance as a function of \% change in production and the type of response (as defined by shape parameter $a$ ) 
of recruitment and growth, and suffer sufficiently low levels of mortality, to tolerate regular trawling disturbance. Since the range of disturbances recorded at our study sites span the range recorded on most beam trawling grounds in the North Sea (e.g. Rijnsdorp et al. 1998), our results suggest that the production and biomass of smaller infauna are largely unaffected by trawling disturbance on sand-mud sediments. Most of the diet of 11 to $25 \mathrm{~cm}$ sole, 11 to $30 \mathrm{~cm}$ dab and 11 to $35 \mathrm{~cm}$ plaice consists of polychaetes (Braber \& De Groot 1973, Rijnsdorp \& Vingerhoed 2001). Siphons of bivalve molluscs are important in the diet of larger plaice (Braber \& De Groot 1973), but these fish are an increasingly small component of the fishery following intensive exploitation of the plaice stock (Rijnsdorp \& Millner 1996). In general, beam trawling appears to have created a system where small fish feed on small food items. This may have minimal effects on the growth and production of flatfishes, but the size structure, biomass and total production of the infaunal and fish communities are fundamentally different from those in the unfished state.

While the production of small animals that support commercial fish species was not reduced by trawling disturbance, the role of the infaunal community will change following chronic trawling disturbance. Polychaetes and small infauna dominate the benthic fauna in heavily trawled areas, because populations of larger species are greatly depleted (Frid et al. 1999, Kaiser et al. 2000, Jennings et al. 2001a), and yet the smaller infauna are much less significant as bioturbators (Swift 1993). As a result, sediment community function, carbon mineralisation and biogeochemcial fluxes are likely to be strongly affected by trawling activity because the physical effects of trawling are equivalent to those of an extreme bioturbator, and yet, unlike bioturbating macrofauna, trawling does not directly contribute to community metabolism (Duplisea et al. 2001).

There are 2 principal concerns about our method of assessing infaunal production. First, we could not consider the effects of differential fish predation in the areas subject to different levels of trawling disturbance. We might expect that fish are more abundant in areas where trawlers operate, and that our production estimates will be biased down in those areas. Equally, fishing may deplete the abundance of fish in the trawled areas and therefore release infauna from predation. Long-term estimates of changes in the abundance of fishes at small spatial scales are not available and we cannot therefore determine whether they biased our results. Second, our production estimates may underestimate decreases in production as mortality rates rise. This is because the $\mathrm{P}: \mathrm{B}$ ratio will reflect recruitment and growth. We assumed that the $\mathrm{P}: \mathrm{B}$ ratio increased continuously as body size fell, but if the mean size of a population tends below the size at maturity, recruitment will be impaired. As a result, larger species that are present in the community at low mean body size may only have the capacity for individual rather than population growth. 
Table 5. Calculated production of infauna and polychaetes (ash-free dry mass [AFDM] > 0.78 to $62.5 \mathrm{mg}$ )

\begin{tabular}{|c|c|c|c|}
\hline $\begin{array}{l}\text { Site/ } \\
\text { box code }\end{array}$ & $\begin{array}{l}\text { Infauna production } \\
\left(\mathrm{AFDM} \mathrm{g} \mathrm{m} \mathrm{m}^{-2} \mathrm{yr}^{-1}\right)\end{array}$ & 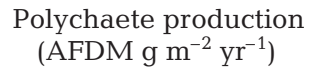 & $\begin{array}{l}\text { Polychaete production } \\
\text { as \% infauna production }\end{array}$ \\
\hline $1 \mathrm{~A}$ & 2.16 & 0.91 & 0.42 \\
\hline $1 \mathrm{~B}$ & 1.93 & 0.88 & 0.46 \\
\hline $1 \mathrm{C}$ & 2.00 & 1.19 & 0.59 \\
\hline $2 \mathrm{~A}$ & 3.15 & 1.43 & 0.45 \\
\hline $2 \mathrm{~B}$ & 2.68 & 1.28 & 0.48 \\
\hline $2 \mathrm{C}$ & 1.45 & 0.76 & 0.52 \\
\hline $3 \mathrm{~A}$ & 2.31 & 1.18 & 0.51 \\
\hline $3 \mathrm{~B}$ & 2.16 & 0.73 & 0.34 \\
\hline $3 C$ & 1.89 & 0.74 & 0.39 \\
\hline $4 \mathrm{~A}$ & 1.85 & 0.95 & 0.51 \\
\hline 4B & 1.58 & 0.88 & 0.56 \\
\hline $4 \mathrm{C}$ & 1.60 & 0.86 & 0.54 \\
\hline $5 \mathrm{~A}$ & 1.87 & 0.86 & 0.46 \\
\hline $5 B$ & 1.36 & 0.61 & 0.45 \\
\hline $5 \mathrm{C}$ & 1.43 & 0.62 & 0.44 \\
\hline $6 \mathrm{~A}$ & 0.98 & 0.50 & 0.51 \\
\hline $6 \mathrm{~B}$ & 0.60 & 0.53 & 0.88 \\
\hline $6 \mathrm{C}$ & 0.98 & 0.49 & 0.50 \\
\hline $7 \mathrm{~A}$ & 0.52 & 0.42 & 0.82 \\
\hline $7 B$ & 0.57 & 0.38 & 0.67 \\
\hline $7 \mathrm{C}$ & 0.64 & 0.61 & 0.95 \\
\hline $8 \mathrm{~A}$ & 1.53 & 0.79 & 0.51 \\
\hline $8 \mathrm{~B}$ & 1.77 & 1.07 & 0.61 \\
\hline $8 C$ & 1.15 & 0.65 & 0.57 \\
\hline $9 \mathrm{~A}$ & 1.55 & 0.71 & 0.46 \\
\hline $9 B$ & 1.37 & 1.03 & 0.75 \\
\hline $9 \mathrm{C}$ & 0.91 & 0.38 & 0.41 \\
\hline
\end{tabular}

If the patchiness of trawling effort is maintained at present levels, our study suggests that the production of fish food on flatfish trawling grounds is unlikely to be compromised by trawling disturbance. However, trawling disturbance will reduce the biomass of many larger species and affect biogeochemical processes. Given the power of our analyses and the lack of evidence for the increased production of small infauna at intermediate levels of disturbance, recent increases in the production of small benthic infauna in the North Sea are more likely to reflect increases in primary production following climate change (Kroncke et al. 1998, Reid et al. 1998), and the tolerance of the small polychaetes and bivalves to trawling disturbance. This conclusion could only have been reached by comparing the spatial impacts of trawling with existing analyses of temporal trends in the abun-

The production of smaller infauna in heavily trawled areas may be sustained by the settlement and growth of recruits from adjacent undisturbed habitats. Our analysis does not allow us to identify the relative role of recruitment in mitigating the effects of trawling, but for practical purposes, consistent patchiness in trawling effort will help to limit the overall impacts of trawling. In the absence of changes to management strategies that result in the relocation of effort, the spatial distribution of trawling effort is quite consistent from year to year because trawlers will tend to return to tows that are stored on their navigation systems and known to be clear of obstructions (Rijnsdorp et al. 1998). In the North Sea and at the scale of the ICES rectangle (211 rectangles of $0.5^{\circ}$ latitude by $1^{\circ}$ longitude: area of rectangle $3720 \mathrm{~km}^{2}$ at $53^{\circ} \mathrm{N}$ ), $50 \%$ of rectangles are beam-trawled for less than $2000 \mathrm{~h} \mathrm{yr}^{-1}$. Since a typical beam trawler will impact $534.5 \mathrm{~km}^{2}$ of seabed in $2000 \mathrm{~h}$ (Jennings et al. 2001b), it will take at least $7 \mathrm{yr}$ to trawl an entire rectangle if it is fished for less than $2000 \mathrm{~h} \mathrm{yr}^{-1}$. Such infrequent trawling would have a small effect on most benthic fauna. We suggest that fishery management strategies that lead to patchy but temporally stable patterns of trawling will often have lower total impacts on benthic communities than strategies that lead to more homogeneous and temporally unstable distribution of the same effort. dance of North Sea infauna and shows why both spatial and temporal analyses should be considered when making any assessment of the impacts of fishing.

Acknowledgements. We thank Nic Denney, Chris Firmin, Alison Hewer, Paul Hudson, Steve Lovewell, Tracy Mead, Dave Palmer, Michaela Schratzberger, Christie Stewart, Chris Sweeting, Peter Walker, Karema Warr and the officers and crew of RV 'Corystes' for practical assistance with sample collection. Claire Mason conducted the particle size analyses, Karema Warr maintained the fishing effort database and Thomas Brey provided unpublished data on mass conversions for benthic invertebrates. The work was funded by the Department for Environment, Food and Rural Affairs, UK, through the MF07 'Impacts of fishing' programme (Projects MF0716 and MF0731).

\section{LITERATURE CITED}

Auster PJ, Langton RW (1999) The effects of fishing on fish habitat. Am Fish Soc Symp 22:150-187

Bergman MJN, Van Santbrink JW (2000a) Fishing mortality of populations of megafauna in sandy sediments. In: Kaiser MJ, De Groot SJ (eds) Effects of fishing on nontarget species and habitats: biological, conservation and socio-economic issues. Blackwell Science, Oxford, p 49-68

Bergman MJN, Van Santbrink JW (2000b) Mortality in megafaunal benthic populations caused by trawl fisheries on the Dutch continental shelf in the North Sea in 1994. ICES J Mar Sci 57:1321-1331

Braber L, De Groot, SJ (1973) The food of five flatfish species 
(Pleuronectiformes) in the southern North Sea. Neth J Sea Res 6:163-172

Brey $\mathrm{T}$ (1990) Estimating productivity of macrobenthic invertebrates from biomass and mean individual weight. Meeresforschung 32:329-343

Brey T (1999) Growth performance and mortality in aquatic macrobenthic invertebrates. Adv Mar Biol 35:153-223

Clarke KR, Ainsworth M (1993) A method of linking multivariate community structure to environmental variables. Mar Ecol Prog Ser 92:205-219

Collie JS, Escanero GA, Valentine PC (1997) Effects of bottom fishing on the benthic megafauna of Georges Bank. Mar Ecol Prog Ser 155:159-172

Collie JS, Escanero GA, Valentine PC (2000a) Photographic evaluation of the impacts of bottom fishing on benthic epifauna. ICES J Mar Sci 57:987-1001

Collie JS, Hall SJ, Kaiser MJ, Poiner IR (2000b) A quantitative analysis of fishing impacts on shelf sea benthos. J Anim Ecol 69:785-798

De Clerck R, Buseyne D (1989) On the feeding of plaice (Pleuronectes platessa L.) in the southern North Sea. ICES-CM 1989/G:23

De Groot SJ, Lindeboom HJ (1994) Environmental impact of bottom gears on benthic fauna in relation to natural resources management and protection of the North Sea. Netherlands Institute for Sea Research, Texel

Duplisea DE (2000) Benthic organism size-spectra in the Baltic Sea in relation to the sediment environment. Limnol Oceanogr 45:558-568

Duplisea DE, Jennings S, Malcolm SJ, Parker R, Sivyer D (2001) Modelling the potential impacts of bottom trawl fisheries on soft sediment biochemistry in the North Sea. Geochem Trans 14:1-6

Duplisea DE, Jennings S, Warr KJ, Dinmore TA (in press) A size-based model to predict the impacts of bottom trawling on benthic community structure. Can J Fish Aquat Sci

Dyer KR (1986) Coastal and estuarine sediment dynamics. John Wiley \& Sons, Chichester

Frid CLJ, Clark RA, Hall JA (1999) Long-term changes in the benthos on a heavily fished ground off the NE coast of England. Mar Ecol Prog Ser 188:13-20

Gilkinson KM, Paulin M, Hurley S, Schwinghamer P (1998) Impacts of trawl door scouring on infaunal bivalves: results of a physical trawl door model/dense sand interaction. J Exp Mar Biol Ecol 224:291-312

Hall SJ (1994) Physical disturbance and marine benthic communities: life in unconsolidated sediments. Oceanogr Mar Biol Annu Rev 32:179-239

Hall SJ (1999) The effects of fishing on marine ecosystems and communities. Blackwell Science, Oxford

Hastie TJ, Tibshirani RJ (1990) Generalized additive models. Chapman \& Hall, London

Jennings S, Kaiser MJ (1998) The effects of fishing on marine ecosystems. Adv Mar Biol 34:201-352

Jennings S, Warr KJ, Greenstreet SPR, Cotter AJ (2000) Spatial and temporal patterns in North Sea fishing effort. In: Kaiser MJ, De Groot SJ (eds) Effects of fishing on nontarget species and habitats: biological conservation and socio-economic issues. Blackwell Science, Oxford, p 3-14

Jennings S, Dinmore TA, Duplisea DE, Warr KJ, Lancaster JE (2001a) Trawling disturbance can modify benthic production processes. J Anim Ecol 70:459-475

Jennings S, Pinnegar JK, Polunin NVC, Warr KJ (2001b) Impacts of trawling disturbance on the trophic structure of benthic invertebrate communities. Mar Ecol Prog Ser 213: $127-142$

Kaiser MJ, De Groot SJ (2000) The effects of fishing on non- target species and habitats: biological, conservation and socio-economic issues. Blackwell Science, Oxford

Kaiser MJ, Rogers SI, Ellis JR (1999) Importance of benthic habitat complexity for demersal fish assemblages. Am Fish Soc Symp 22:212-223

Kaiser MJ, Ramsay K, Richardson CA, Spence FE, Brand AR (2000) Chronic fishing disturbance has changed shelf sea benthic community structure. J Anim Ecol 69:494-503

Kenchington EL, Prena RJ, Gilkinson KJ, Gordon DC and 6 others (2001) Effects of experimental otter trawling on the macrofauna of a sandy bottom ecosystem on the Grand Banks of Newfoundland. Can J Fish Aquat Sci 58:1043-1057

Koslow JA, Gowlett-Holmes K, Lowry JK, O'Hara T, Poore GCB, Williams A (2001) Seamount benthic macrofauna off southern Tasmania: community structure and impacts of trawling. Mar Ecol Prog Ser 213:111-125

Kroncke I, Dippner JW, Heyen H, Zeiss B (1998) Long-term changes in macrofaunal communities off Norderney (East Frisia, Germany) in relation to climate variability. Mar Ecol Prog Ser 167:25-36

Lindeboom HJ, De Groot SJ (1998) The effects of different types of fisheries on the North Sea and Irish Sea benthic ecosystems. Netherlands Institute of Sea Research, Texel

Peterman RM, M'Gonigle M (1992) Statistical power analysis and the precautionary principle. Mar Poll Bull 24:231-234

Ramsay K, Kaiser MJ, Moore PG, Hughes RN (1997) Consumption of fisheries discards by benthic scavengers: utilisation of energy subsidies in different marine habitats. J Anim Ecol 66:884-896

Reid PC, Edwards M, Hunt HG, Warner AJ (1998) Phytoplankton change in North Atlantic. Nature 391:546

Rijnsdorp AD, Millner RS (1996) Trends in population dynamics and exploitation of North Sea plaice (Pleuronectes platessa L.) since the late 1800s. ICES J Mar Sci 53:1170-1184

Rijnsdorp AD, Van Leeuwen PI (1996) Changes in growth of North Sea plaice since 1950 in relation to density, eutrophication, beam-trawl effort and temperature. ICES J Mar Sci 53:1199-1213

Rijnsdorp AD, Vingerhoed B (2001) Feeding of plaice Pleuronectes platessa L. and sole Solea solea (L.) in relation to the effects of bottom trawling. J Sea Res 45:219-229

Rijnsdorp AD, Bujis AM, Storbeck F, Visser E (1998) Microscale distribution of beam trawl effort in the southern North Sea between 1993 and 1996 in relation to the trawling frequency of the sea bed and the distribution of benthic organisms. ICES J Mar Sci 55:403-419

Rumohr H, Krost P (1991) Experimental evidence of damage to the benthos by bottom trawling with special reference to Arctica islandica. Meeresforschung 33:340-345

Rumohr H, Kujawski T (2000) The impact of a trawl fishery on the epifauna of the southern North Sea. ICES J Mar Sci 57 : 1389-1394

Schwinghamer P, Hargrave B, Peer D, Hawkins CM (1986) Partitioning of production and respiration among size groups of organisms in an intertidal benthic community. Mar Ecol Prog Ser 31:131-142

Swift DJ (1993) The macrobenthic infauna off Sellafield (North-eastern Irish Sea) with special reference to bioturbation. J Mar Biol Assoc UK 73:143-162

Thrush SF, Hewitt JE, Cumings VJ, Dayton PK and 6 others (1998) Disturbance of the marine benthic habitat by commercial fishing: impacts at the scale of the fishery. Ecol Appl 8:866-879

Thrush SF, Hewitt JE, Funnell GA, Cummings VJ, Ellis J, Schultz D, Talley D, Norkko A (2001) Fishing disturbance and marine biodiversity: role of habitat structure in simple soft-sediment systems. Mar Ecol Prog Ser 221:255-264 